Research Article

\title{
Serum ADAMTS-13 Levels as an Indicator of Portal Vein Thrombosis
}

\author{
Tomasz Mikuła (D), ${ }^{1}$ Joanna Kozłowska, ${ }^{1}$ Wojciech Stańczak, ${ }^{1}$ Mariusz Sapuła, ${ }^{1}$ \\ Aleksandra Różyk, ${ }^{2}$ and Alicja Wiercińska-Drapało ${ }^{1}$ \\ ${ }^{1}$ Department of Infectious and Tropical Diseases and Hepatology, Medical University of Warsaw, Warsaw, Poland \\ ${ }^{2}$ Science Students' Society of the Department of Infectious and Tropical Diseases and Hepatology, Medical University of Warsaw, \\ Warsaw, Poland
}

Correspondence should be addressed to Tomasz Mikuła; tomasz.mikula6@wp.pl

Received 12 July 2017; Revised 21 January 2018; Accepted 20 February 2018; Published 18 April 2018

Academic Editor: Alfred Gangl

Copyright (c) 2018 Tomasz Mikuła et al. This is an open access article distributed under the Creative Commons Attribution License, which permits unrestricted use, distribution, and reproduction in any medium, provided the original work is properly cited.

Background. Coagulation disorders in patients with liver cirrhosis are a common clinical problem. Cirrhosis should be considered a state of impaired blood clotting or an imbalance of the whole coagulation system. Cirrhosis-induced coagulopathy encompasses disturbances in both the procoagulant and anticoagulant systems. This mechanism may promote the development of thrombosis with portal vein thrombosis (PVT), which is considered an obstacle to orthotopic liver transplantation (OLT). We assessed serum ADAMTS-13 levels in patients with decompensated liver cirrhosis, with and without PVT. Material and Methods. Serum ADAMTS-13 levels, age, platelet count (PLT), and INR (international normalized ratio) were evaluated in $(n=64)$ patients with liver cirrhosis either with PVT (group $1, n=31)$ or without PVT (group 2, $n=33$ ). The results were compared with those from healthy volunteers (group $3, n=37$ ). Liver cirrhosis was based on Desmet's classification of chronic hepatitis in liver biopsy stage $\geq 3$ or liver elastography F-score $\geq 3$. Serum ADAMTS13 levels were measured with Quantikine ${ }^{\circledR}$ ELISA Human ADAMTS13 Immunoassay, R\&D Systems Inc. We used Welch's F-test, Games-Howell, one-way ANOVA, Bonferroni test, and logistic regression to determine whether ADAMTS-13 levels were a predictor that was independent of MELD and Child-Pugh scores. All results $(P<0.05)$ were considered statistically significant. Results. The mean serum ADAMTS-13 level in patients with PVT was significantly lower than that in patients without PVT $(P=0.001)$ and controls $(P=0.001)$. The mean serum ADAMTS-13 level in patients without PVT was significantly lower than that in controls $(P=0.001)$. ADAMTS-13 levels were significantly associated with PVT accounting for the Child-Pugh or MELD score in the logistic regression model. Conclusions. Low serum ADAMTS-13 levels can be a useful indicator of portal thrombosis in patients with decompensated liver cirrhosis irrespective of Child-Pugh or MELD scores. Further research is needed to determine whether ADAMTS-13 levels will find use in everyday clinical practice.

\section{Introduction}

Liver functions include the synthesis of vitamin $\mathrm{K}$ dependent clotting factors. Thus, an impaired liver function leads to an increased bleeding tendency caused by a deficiency of those factors and of thrombocytes. On the other hand, liver cirrhosis may promote the development of thrombosis, specifically portal vein thrombosis (PVT), which is considered an obstacle in orthotopic liver transplantation (OLT).

Cirrhosis-induced coagulopathy encompasses disturbances in both the procoagulant and anticoagulant systems, 
rendering compensatory hemostatic mechanisms ineffective in cirrhotic patients. Cirrhosis should be considered a state of impaired blood clotting or, more specifically, an imbalance of the whole coagulation system.

Bleeding esophageal varices and portal hypertensive gastropathy are common complications of advanced, decompensated liver disease. According to population studies, portal vein thrombosis (PVT) is observed in approximately $40 \%$ of cirrhotic patients. PVT results in worse clinical outcomes, causes portal hypertension with its complications, and is associated with lower survival of transplant recipients. PVT pathogenesis encompasses local risk factors, such as endothelial activation and stagnant portal blood flow, as well as systemic ones: increased activity of von Willebrand factor, high levels of factor VIII, or reduced antithrombin, protein $\mathrm{C}$, and protein S levels. Anticoagulants, specifically low-molecular-weight heparin, have been proven to be effective in both the treatment and the prevention of PVT [1].

The ADAM (a disintegrin-like and metalloproteinase) proteins, with their subfamily of ADAMTS (a disintegrinlike and metalloproteinase with thrombospondin motif) proteins, are produced exclusively by hepatic stellate cells and play an important regulatory role in coagulation. The ADAMTS proteins are involved in many different processes, such as proteolysis of proteoglycans (ADAMTS-1, 4, 5, 8, and 9) or degradation of cartilage oligomeric matrix protein (ADAMTS-7 and 12).

The ADAMTS-13 protein is an enzyme, Willebrand factor-cleaving protease (vWFCP). In vascular injury, von Willebrand factor (vWF) together with platelets initiates the formation of thrombus. It also serves as a carrier for factor VIII in plasma. Its deficiency is responsible for von Willebrand's disease and can lead to oncogenesis $[2,3]$.

Functional deficiency of ADAMTS-13 results in the presence of unusually large VWF multimers (UL-VWFMs) in the plasma, which promotes platelet aggregation and thrombus formation. This process is linked to thrombotic thrombocytopenic purpura (TTP), first described by Moschcowitz [4]. TTP is presented as thrombocytopenia and microangiopathic hemolysis, which, if severe, can lead to organ dysfunction. The presence of UL-VWFMs in the plasma is a characteristic feature of this disease [5]. Considering that UL-VWFMs are produced at the sites of vascular injury, ADAMTS-13 deficiency can also be associated with cardiovascular disease, ischemic stroke, and liver disease $[6,7]$. In the healthy population, serum ADAMTS-13 levels range from 515 to $1644 \mathrm{ng} / \mathrm{mL}, S D \pm 207 \mathrm{ng} / \mathrm{mL}$ (Quantikine ELISA Human ADAMTS13 Immunoassay, R\&D Systems Inc.) [8].

\section{Aim}

The aim of this study is to evaluate serum ADAMTS-13 levels as a marker of portal vein thrombosis (PVT) in patients with decompensated liver cirrhosis of various origins.

\section{Material and Methods}

We analyzed $(n=64)$ patients with decompensated liver cirrhosis of various origins (HBV, $n=10$; HBV/alcohol, $n=3 ; \mathrm{HBV} / \mathrm{HCV}, n=1 ; \mathrm{HCV}, n=28 ; \mathrm{HCV} /$ alcohol, $n=14$; alcohol, $n=5$; and PBC (primary biliary cirrhosis), $n=3$ ) divided into two groups: group 1 with PVT $(n=31 ; 15$ females/16 males) and group 2 without PVT $(n=33 ; 14$ females/19 males).

The results were compared with those of healthy controls (group 3; $n=37 ; 19$ females/16 males). The inclusion criteria for groups 1 and 2 were at least one episode of decompensated liver cirrhosis in the past or present. The exclusion criterion is no history of liver decompensation or other chronic liver diseases. None of the participants of our study had sepsis, DIC, or cancer.

The diagnosis of liver cirrhosis was based on Desmet's classification of chronic hepatitis in liver biopsy specimens (stage $\geq 3$ ) or liver stiffness assessed via elastography (Fscore $\geq 3$ ). The presence of portal thrombosis was based on at least two methods of abdominal ultrasonography (USG), computed tomography (CT), or magnetic resonance imaging (MRI).

Serum ADAMTS-13 levels were measured with Quantikine ELISA Human ADAMTS13 Immunoassay, R\&D Systems Inc. Furthermore, platelet count (PLT) and INR values were evaluated. We used Welch's F-test to determine a possible correlation between ADAMTS-13 levels or INR (i.e., variables that were heteroscedastic according to Levene's test) and PVT status. A post hoc analysis was performed using the Games-Howell test for these two variables: ADAMTS-13 levels and INR. As for age and platelet count (i.e., variables that were homoscedastic according to Levene's test), we used the one-way ANOVA to check for any association between these variables and PVT status. A post hoc analysis was performed using the Bonferroni test. Logistic regression was used to determine whether ADAMTS-13 levels were a predictor that was independent of MELD and Child-Pugh scores. Informed consent was obtained from all individual participants included in the study.

\section{Results}

We found a significant difference in ADAMTS-13 levels between patients with and without PVT $(P=0.001)$. The two groups of cirrhotic patients (with and without PVT) were comparable in terms of age, INR, and platelet count.

The control group in our study exhibited significantly higher mean ADAMTS-13 levels than either of the groups of patients with cirrhosis. As expected, healthy volunteers displayed significantly higher platelet counts and lower INR values than cirrhotic patients, although the control group was younger than the other two (mean age of controls 39.7 years, mean age of patients with PVT 57.7 years, and mean age of patients without PVT 52.6 years; the difference between the control group and either of the other groups was statistically significant, whereas the difference between the two cirrhotic groups was statistically insignificant).

In our study, both Child-Pugh and MELD scores correlated negatively with ADAMTS-13 levels (for ADAMTS13 and Child-Pugh score: $r=-0.47$ and $P<0.01$; for ADAMTS-13 and MELD score: $r=-0.41$ and $P<0.01$ ). While it is true that Child-Pugh and MELD scores were 
TABLE 1: Baseline characteristics of the analyzed groups.

\begin{tabular}{lccc}
\hline & $\begin{array}{c}\text { Patients } \\
\text { with PVT } \\
\text { Group 1 } \\
(n=31) \\
(\text { Mean } \pm \text { SD })\end{array}$ & $\begin{array}{c}\text { Patients } \\
\text { without PVT } \\
\text { Group 2 } \\
(n=33) \\
(\text { Mean } \pm \text { SD })\end{array}$ & $\begin{array}{c}\text { Healthy } \\
\text { controls } \\
\text { Group 3 } \\
(n=37) \\
(\text { Mean } \pm \text { SD })\end{array}$ \\
\hline $\begin{array}{l}\text { Age (years }) \\
\text { ADAMTS-13 } \\
(\mathrm{ng} / \mathrm{mL})\end{array}$ & $695 \pm 12.9$ & $52.6 \pm 12.6$ & $39.7 \pm 8.9$ \\
$\mathrm{PLT} \times 10^{3} / \mu \mathrm{L}$ & $116 \pm 69$ & $1069 \pm 110$ & $1301 \pm 203$ \\
$\mathrm{INR}$ & $1.38 \pm 0.29$ & $110 \pm 63$ & $239 \pm 79$ \\
\hline
\end{tabular}

TABLE 2: Comparison of the analyzed markers in group 1 (with PVT) and group 2 (without PVT).

\begin{tabular}{lccc}
\hline & $\begin{array}{c}\text { Patients } \\
\text { with PVT } \\
\text { Group 1 } \\
(n=31) \\
(\text { Mean } \pm \text { SD })\end{array}$ & $\begin{array}{c}\text { Patients } \\
\text { without PVT } \\
\text { Group 2 } \\
(n=33) \\
(\text { Mean } \pm \text { SD })\end{array}$ & $P$ value \\
\hline Age $($ years $)$ & $57.7 \pm 12.9$ & $52.6 \pm 12.6$ & 0.23 \\
ADAMTS-13 $(\mathrm{ng} / \mathrm{mL})$ & $695 \pm 144$ & $1069 \pm 109$ & $<0.05$ \\
$\mathrm{PLT} \times 10^{3} / \mu \mathrm{L}$ & $116 \pm 69$ & $110 \pm 63$ & 0.99 \\
$\mathrm{INR}$ & $1.38 \pm 0.29$ & $1.36 \pm 0.29$ & 0.96 \\
\hline
\end{tabular}

TABLE 3: Comparison of the analyzed markers in group 1 (with PVT) and group 3 (healthy volunteers).

\begin{tabular}{lccc}
\hline & $\begin{array}{c}\text { Patients } \\
\text { with PVT } \\
\text { Group 1 }(n=31) \\
(\text { Mean } \pm \text { SD })\end{array}$ & $\begin{array}{c}\text { Control } \\
\text { Group 3 } \\
(n=37) \\
(\text { Mean } \pm \text { SD })\end{array}$ & $P$ value \\
\hline Age (years) & $57.7 \pm 12.9$ & $39.7 \pm 8.9$ & $<0.05$ \\
ADAMTS-13 (ng/mL) & $695 \pm 144$ & $1301 \pm 203$ & $<0.05$ \\
PLT $\times 10^{3} / \mu \mathrm{L}$ & $116 \pm 69$ & $239 \pm 79$ & $<0.05$ \\
INR & $1.38 \pm 0.29$ & $1.04 \pm 0.08$ & $<0.05$ \\
\hline
\end{tabular}

significantly different in groups 1 and 2, ADAMTS-13 levels were still significantly associated with PVT even in logistic regression models accounting for either Child-Pugh score and ADAMTS-13 levels or MELS score and ADAMTS13 levels.

All data are presented in Tables 1-5.

\section{Discussion}

It should be noted that serum ADAMTS-13 levels are not routinely measured as part of everyday clinical practice. Despite the various existing studies on this enzyme, which emphasize its role in regulating coagulation or in cardiovascular disease and ischemic stroke pathophysiology, the clinical implications and possible treatment perspectives for this enzyme in hepatology remain not fully understood. Lancellotti et al. assessed serum ADAMTS-13 levels in patients with and without PVT and reported a strong correlation between low ADAMTS-13 levels and the presence of PVT.
TABLE 4: Comparison of the analyzed markers in group 2 (without PVT) and group 3 (healthy volunteers).

\begin{tabular}{lccc}
\hline & $\begin{array}{c}\text { Patients } \\
\text { without PVT } \\
\text { Group 2 }(n=33) \\
(\text { Mean } \pm \text { SD })\end{array}$ & $\begin{array}{c}\text { Control } \\
\text { Group 3 } \\
(n=37) \\
(\text { Mean } \pm \text { SD })\end{array}$ & $P$ value \\
\hline Age (years) & $52.6 \pm 12.6$ & $39.7 \pm 8.9$ & $<0.05$ \\
ADAMTS-13 $(\mathrm{ng} / \mathrm{mL})$ & $1069 \pm 110$ & $1301 \pm 203$ & $<0.05$ \\
$\mathrm{PLT} \times 10^{3} / \mu \mathrm{L}$ & $110 \pm 63$ & $239 \pm 79$ & $<0.05$ \\
$\mathrm{INR}$ & $1.36 \pm 0.29$ & $1.04 \pm 0.08$ & $<0.05$ \\
\hline
\end{tabular}

TABle 5: Comparison of Child-Pugh and MELD scores in both groups.

\begin{tabular}{lccc}
\hline & $\begin{array}{c}\text { Patients } \\
\text { with PVT } \\
\text { Group 1 }(n=31) \\
(\text { Mean } \pm \text { SD })\end{array}$ & $\begin{array}{c}\text { Patients } \\
\text { without PVT } \\
\text { Group 2 }(n=33) \\
(\text { Mean } \pm \text { SD })\end{array}$ & $P$ value \\
\hline Child-Pugh score & $8.0 \pm 2.0$ & $6.4 \pm 1.3$ & $<0.05$ \\
MELD score & $17.0 \pm 7.3$ & $11.9 \pm 5.8$ & $<0.05$ \\
\hline
\end{tabular}

The study included twenty-four patients with PVT and sixty patients without PVT and demonstrated significantly lower ADAMTS-13 levels in the group with PVT (median 16.8 versus $69.1 \%, P=0.0047$ ) [9].

These results are consistent with the findings of our study, as we also reported a significant difference in ADAMTS-13 levels between patients with and without PVT $(P=0.001)$. Somewhat different results were reported by Wiese et al., who evaluated serum ADAMTS-13 levels in 61 cirrhotic patients (Child-Pugh classification: class A $n=22$, class $\mathrm{B} n=21$, and class $\mathrm{C} n=18$ ) and a control group, consisting of 9 healthy individuals. All participants underwent hepatic vein catheterization to obtain hepatic venous pressure gradient (HVPG); ADAMTS-13 antigen levels were measured in the plasma collected from hepatic veins and a femoral artery. Serum ADAMTS-13 levels were higher in cirrhotic patients than in the control group $(P<0.03)$. However, there was no significant correlation between ADAMTS-13 levels and the Child-Pugh score, HVPG, systemic vascular resistance (SVR), or cardiac output (CO). Furthermore, there was no significant association between serum ADAMTS-13 levels and disease severity or hemodynamic changes [10]. A recent study by Goel et al. analyzed the ADAMTS-13:vWF ratio in patients with idiopathic noncirrhotic intrahepatic portal hypertension (NCIPH). The authors concluded that ADAMTS-13 deficiency was independently associated with NCIPH [11]. Contrary to an earlier study by Song et al., we reported a correlation between ADAMTS-13 levels and platelet count. This discrepancy in findings may be due to the fact that Song et al. enrolled patients with sepsis- or cancer-induced coagulopathy, whereas our study population is comprised simply of patients with or without PVT [12]. Groeneveld et al. recently published quite a unique study investigating the ADAMTS-13:vWF ratio in patients after major partial hepatectomy. The findings confirmed that an imbalance of 
this ratio leads to an increased risk of systemic venous thrombosis or PVT [13].

Similar to our findings, Uemura et al. found a negative correlation between ADAMTS-13 levels and the severity of liver cirrhosis measured in the Child-Pugh score [14].

As the etiology of liver cirrhosis was classified into seven different groups with relatively small group sizes, we did not attempt to determine whether there is an association between ADAMTS-13 levels and the etiology of liver cirrhosis - our study was underpowered to answer these questions.

\section{Conclusion}

The presence of decreased ADAMTS-13 levels in a patient with liver cirrhosis can suggest PVT and warrants further evaluation through medical imaging. However, the findings of this study alone are not sufficient to obviate the need for medical imaging in case of suspicion of PVT, due to the cross-sectional nature of the study and small sample sizes. Further research is needed to determine whether the determination of ADAMTS-13 levels will find use in everyday clinical practice.

\section{Ethical Approval}

All procedures performed in studies involving human participants were in accordance with the ethical standards of the institutional and/or national research committee and with the 1964 Helsinki Declaration and its later amendments or comparable ethical standards.

\section{Conflicts of Interest}

The author and coauthors declare no conflict of interest.

\section{References}

[1] M. Bianchini, L. de Pietri, and E. Villa, "Coagulopathy in liver diseases: complication or therapy?," Digestive Diseases, vol. 32, no. 5, pp. 609-614, 2014.

[2] S. Kumar, N. Rao, and R. Ge, "Emerging roles of ADAMTSs in angiogenesis and cancer," Cancer, vol. 4, no. 4, pp. 1252-1299, 2012.

[3] M. Pépin, A. Kleinjan, D. Hajage et al., "ADAMTS-13 and von Willebrand factor predict venous thromboembolism in patients with cancer," Journal of Thrombosis and Haemostasis, vol. 14, no. 2, pp. 306-315, 2016.

[4] E. Moschcowitz, "An acute febrile pleiochromic anemia with hyaline thrombosis of the terminal arterioles and capillaries: an undescribed disease," Archives of Internal Medicine, vol. 36, no. 1, pp. 89-93, 1925.

[5] M. Furlan and B. Lammle, "Aetiology and pathogenesis of thrombotic thrombocytopenic purpura and haemolytic uraemic syndrome: the role of von Willebrand factor-cleaving protease," Best Practice \& Research Clinical Haematology, vol. 14, no. 2, pp. 437-454, 2001.

[6] A. O. Spiel, J. C. Gilbert, and B. Jilma, "Von Willebrand factor in cardiovascular disease: focus on acute coronary syndromes," Circulation, vol. 117, no. 11, pp. 1449-1459, 2008.
[7] T. Miyata, K. Kokame, M. Matsumoto, and Y. Fujimura, "ADAMTS13 activity and genetic mutations in Japan," Hämostaseologie, vol. 33, no. 2, pp. 131-137, 2013.

[8] "Human ADAMTS13 Immunoassay, Quantikine ${ }^{\circledR}$ ELISA. Catalog Number DADT130,” https://resources.rndsystems. com/pdfs/datasheets/dadt130.pdf.

[9] S. Lancellotti, M. Basso, V. Veca et al., "Presence of portal vein thrombosis in liver cirrhosis is strongly associated with low levels of ADAMTS-13: a pilot study," Internal and Emergency Medicine, vol. 11, no. 7, pp. 959-967, 2016.

[10] S. Wiese, A. Timm, L. B. Nielsen, J. P. Goetze, F. Bendtsen, and S. Møller, "Plasma ADAMTS-13 protein is not associated with portal hypertension or hemodynamic changes in patients with cirrhosis," Digestive and Liver Disease, vol. 48, no. 4, pp. 404408, 2016.

[11] A. Goel, J. E. Elias, C. E. Eapen, B. Ramakrishna, and E. Elias, "Idiopathic non-cirrhotic intrahepatic portal hypertension (NCIPH) - newer insights into pathogenesis and emerging newer treatment options," Journal of Clinical and Experimental Hepatology, vol. 4, no. 3, pp. 247-256, 2014.

[12] J. Song, K. A. Lee, T. S. Park, R. Park, and J. R. Choi, "Linear relationship between ADAMTS13 activity and platelet dynamics even before severe thrombocytopenia," Annals of Clinical \& Laboratory Science, vol. 38, no. 4, pp. 368-375, 2008.

[13] D. J. Groeneveld, E. M. Alkozai, J. Adelmeijer, R. J. Porte, and T. Lisman, "Balance between von Willebrand factor and ADAMTS13 following major partial hepatectomy," British Journal of Surgery, vol. 103, no. 6, pp. 735-743, 2016.

[14] M. Uemura, Y. Fujimura, M. Matsumoto et al., "Comprehensive analysis of ADAMTS13 in patients with liver cirrhosis," Thrombosis and Haemostasis, vol. 99, no. 6, pp. 1019-1029, 2008. 


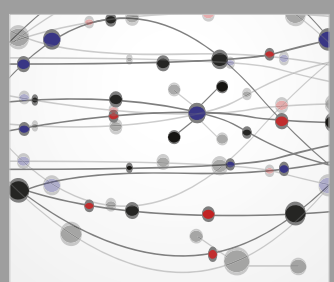

The Scientific World Journal
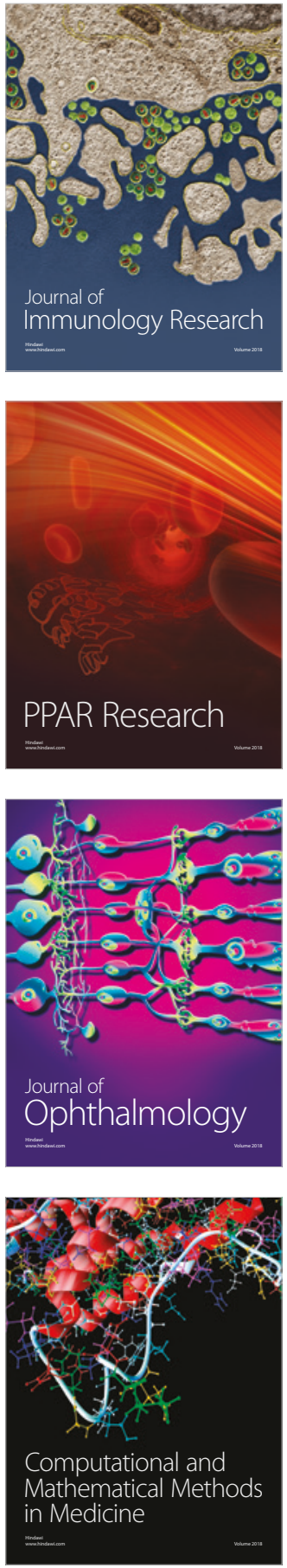

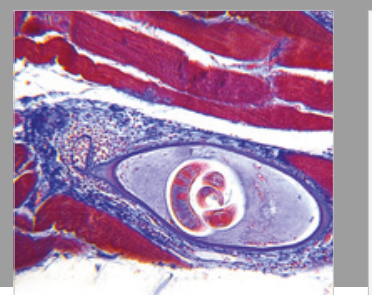

Gastroenterology Research and Practice

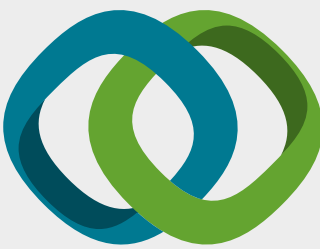

\section{Hindawi}

Submit your manuscripts at

www.hindawi.com
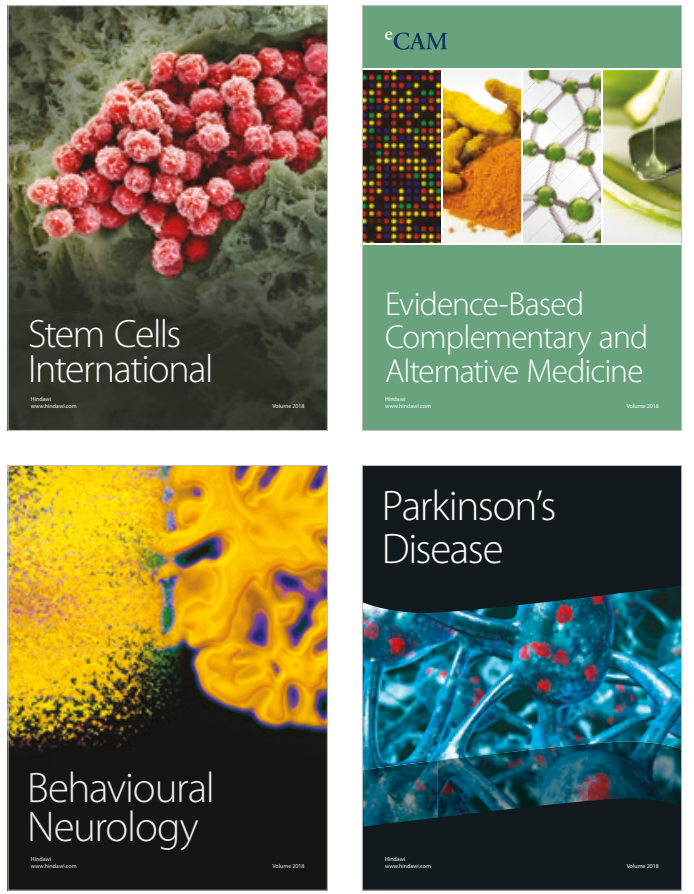

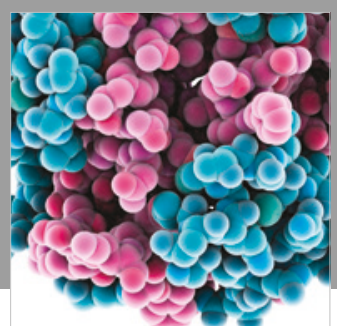

ournal of

Diabetes Research

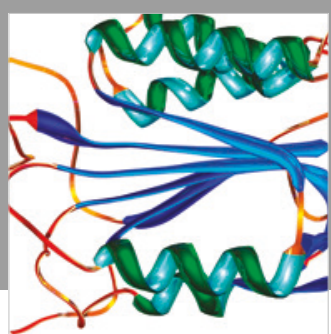

Disease Markers
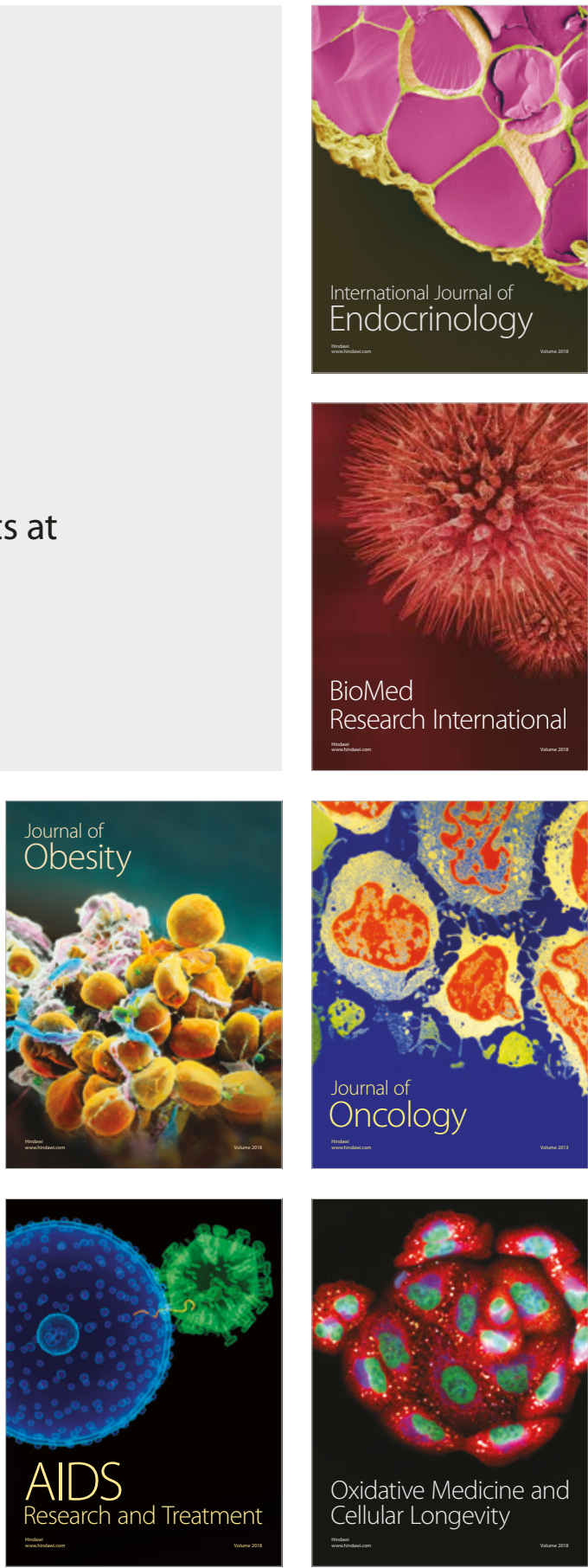